\title{
06
}

\section{Hacia una verdadera arqueología comunitaria}

\author{
Xurxo M. Ayán Vila \\ Proyecto Castro de San Lourenzo \\ (Pobra de Brollón, Lugo) \\ Xosé Gago García-Brabo \\ Proyecto Costa dos Castros (Oia, Pontevedra)
}

Nuestra trayectoria en el ámbito de la socialización del patrimonio se ha venido centrando, en lo que va de siglo XXI, en la puesta en valor de unos yacimientos arqueológicos muy concretos: los castros gallegos. En las últimas décadas de la centuria anterior primaba en Galicia un modelo de arriba abajo; es decir, eran las administraciones, los técnicos y los académicos quienes decidían cómo, cuándo y por qué expropiar, limpiar, excavar y musealizar determinadas áreas arqueológicas. Desde la arqueología del paisaje nos dimos cuenta pronto de que los castros en el mundo rural no solo eran sitios arqueológicos o bienes patrimoniales que había que gestionar en el presente, sino que seguían siendo referentes identitarios, lugares de memoria, hitos en la cartografía simbólica tradicional y espacios de sociabilidad para las comunidades locales. No puede hacerse una verdadera arqueología en comunidad sin tener en cuenta esta realidad. Por otro lado, en estos últimos años, las diferentes coyunturas sociopolíticas y económicas han tenido un impacto enorme en la implicación de la ciudadanía en los proyectos patrimoniales. Así, por ejemplo, la crisis económica ha dado lugar, en la Galicia rural al menos, a todo un proceso de empoderamiento patrimonial por parte de las parroquias y las comunidades de montes, propietarias de facto de la inmensa mayoría de yacimientos arqueológicos. Mientras los expertos debatimos sobre si es pertinente o no la mercantilización del patrimonio, las comunidades rurales comienzan a ver en las piedras una herramienta útil para fijar la población al territorio y apostar por un desarrollo sostenible en la explotación de los recursos forestales y patrimoniales.
Para mostrar todo este proceso, traemos aquí las lecciones que hemos extraído de tres proyectos de arqueología en comunidad en castros gallegos. Todos ellos responden a la misma estrategia de socialización del patrimonio: hemos partido de la propia cultura popular para recuperar el valor simbólico de esos espacios. Primero, la fiesta, la romería, el folklore; después, la investigación arqueológica. En el año 2000 la Asociación de Amigos dos Castros del Ayuntamiento de Cuntis (Pontevedra), después de haber llamado a muchas puertas, nos solicitó asesoría para recuperar el castro de Castrolandín. La comunidad de montes llevó a cabo la deforestación del sitio y cedió los terrenos por cincuenta años. Técnicos y paisanos decidimos que la primera actuación sería recuperar en el castro la antigua festividad del castelo de San Xoán, tradición perdida en la década de 1940. Desde entonces, este lugar es

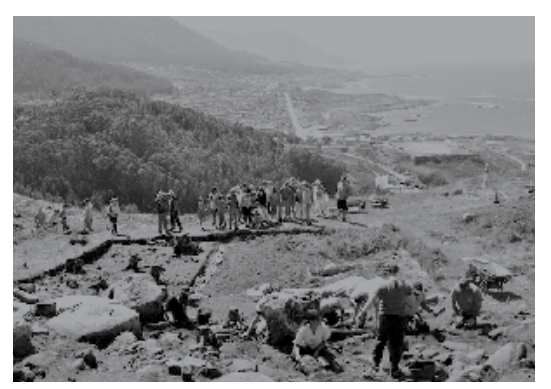

Excavaciones en el castro de A Cabeciña (Pontevedra), en el marco del proyecto Costa dos Castros 


\section{"Las comunidades locales son sujetos activos que adoptan decisiones políticas y son quienes deben marcar, por qué no, la propia agenda arqueológica"}

el escenario de una de las fiestas del solsticio de verano más auténticas de todas las que se hacen en nuestro país. Este proceso de empoderamiento culminó con la creación de la Fundación Terra Termarum Castrolandín, desde la que se han captado fondos europeos para llevar a cabo sucesivas campañas de excavación arqueológica. En Castrolandín aprendimos rápidamente una cosa: las comunidades locales son celosas de su independencia y no pueden ser vistas como meros sujetos pasivos que hay que desarrollar. No. Son sujetos activos que adoptan decisiones políticas y son quienes deben marcar, por qué no, la propia agenda arqueológica.

Los castros de Neixón en Boiro (A Coruña) fueron expropiados por la Xunta a comienzos de este siglo para construir un aula didáctica y hacer visitable el yacimiento. Este espacio era de la comunidad de Cespón desde hace al menos mil años. Obviamente, tras este hecho traumático, la gente no quería saber nada de arqueología en el año 2003, cuando allí desembarcamos. Con nuestro proyecto de campo de trabajo internacional (2003-2008) conseguimos revertir esta situación, mediante el trabajo conjunto con la asociación de vecinos. La colaboración y participación activa en la romería de Neixón en el mes de agosto era fundamental para el desarrollo del proyecto. En Neixón aprendimos que la gente ya no solo quiere gozar de su patrimonio, sino también ser partícipe del propio proceso de generación de conocimiento sobre el pasado. La asunción de una perspectiva multivocal en esa década de 2000 fue de gran utilidad. Pero eso ya no es suficiente en la década de 2010.

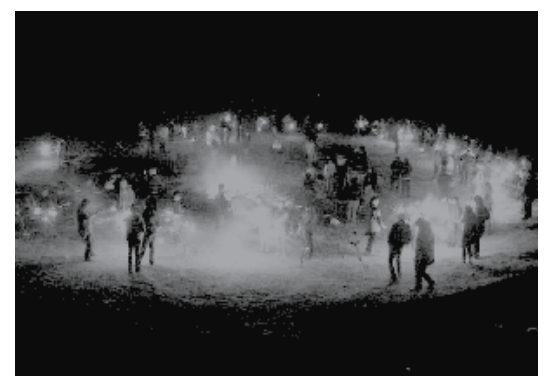

Castelo de San Xoán en el castro de Castrolandín (Cuntis, Pontevedra). Foto Elena Cerviño
En los últimos años llevamos a cabo el proyecto integral Costa dos Castros en el Ayuntamiento de Oia (Pontevedra). Esta iniciativa es pionera porque ha conseguido algo impensable en Galicia: unir a tres comunidades de montes diferentes, crear una imagen de marca conjunta para un territorio y convertir el patrimonio en un recurso sostenible. Nuevamente, los arqueólogos y las arqueólogas asumen su papel de consultores, asesores y ejecutores técnicos. Nuevamente, se echa mano de la tradición oral, de los mitos y las leyendas, para recuperar socialmente petroglifos y castros. Las comunidades locales son las que deciden y gestionan el patrimonio que está en su territorio. Por aquí creemos que van los tiros en el futuro de la gestión patrimonial: la implementación de fórmulas más cercanas a lo que hacen las denominadas arqueologías indígenas en Latinoamérica. El empoderamiento real de las comunidades locales puede superar las limitaciones del modelo de intervención precedente que ha llevado a que el país esté lleno de parques, aulas didácticas y centros de interpretación que ya no es que estén cerrados, es que son auténticas ruinas arqueológicas. Para no repetir estos errores, para no acercarnos de manera paternalista a las comunidades locales, es necesario estimular el debate crítico en las humanidades y ciencias del patrimonio, y para ello es fundamental el papel que juegan cabeceras comprometidas como esta nuestra querida revista $\mathrm{PH}$. 